\title{
Atomic simulations of kinetic friction and its velocity dependence at $\mathrm{Al} / \mathrm{Al}$ and $\alpha-\mathrm{Al}_{2} \mathrm{O}_{3} / \alpha-\mathrm{Al}_{2} \mathrm{O}_{3}$ interfaces
}

\author{
Qing Zhang, ${ }^{1}$ Yue Qi, ${ }^{2}$ Louis G. Hector, Jr., ${ }^{2}$ Tahir Çağın, ${ }^{1}$ and William A. Goddard $\mathrm{III}^{1}$ \\ ${ }^{1}$ Materials and Process Simulation Center (MSC), California Institute of Technology, Pasadena, California 91125, USA \\ ${ }^{2}$ GM Research \& Development Center, Warren, Michigan 48090, USA \\ (Received 15 September 2004; revised manuscript received 1 February 2005; published 5 July 2005)
}

\begin{abstract}
Kinetic friction during dry sliding along atomistic-scale $\mathrm{Al}(001) / \mathrm{Al}(001)$ and $\alpha-\mathrm{Al}_{2} \mathrm{O}_{3}(0001) / \alpha$ $-\mathrm{Al}_{2} \mathrm{O}_{3}(0001)$ interfaces has been investigated using molecular dynamics (MD) with recently developed Reactive Force Fields (ReaxFF). It is of interest to determine if kinetic friction variations predicted with MD follow the macroscopic-scale friction laws known as Coulomb's law (for dry sliding) and Stokes' friction law (for lubricated sliding) over a wide range of sliding velocities. The effects of interfacial commensuration and roughness on kinetic friction have been studied. It is found that kinetic friction during sliding at commensurate $\alpha-\mathrm{Al}_{2} \mathrm{O}_{3}(0001) / \alpha-\mathrm{Al}_{2} \mathrm{O}_{3}(0001)$ interfaces exceeds that due to sliding at an incommensurate $\alpha-\mathrm{Al}_{2} \mathrm{O}_{3}(0001) / \alpha-\mathrm{Al}_{2} \mathrm{O}_{3}(0001)$ interface. For both interfaces, kinetic friction at lower sliding velocities deviates minimally from Coulombic friction, whereas at higher sliding velocities, kinetic friction follows a viscous behavior with sliding damped by thermal phonons. For atomically smooth $\mathrm{Al}(001) / \mathrm{Al}(001)$, only viscous friction is observed. Surface roughness tends to increase kinetic friction, and adhesive transfer causes kinetic friction to increase more rapidly at higher sliding velocities.
\end{abstract}

DOI: 10.1103/PhysRevB.72.045406

PACS number(s): 62.20.Qp, 46.55.+d, 81.40.Pq

\section{INTRODUCTION}

Sliding friction is typically characterized by two macroscopic-scale friction laws, viz. Coulomb's law (for dry sliding) and Stokes' law (for lubricated sliding). First proposed by Charles-Augustin de Coulomb in $1785,{ }^{1}$ the law that bears his name asserts that the kinetic friction force is independent of sliding velocity ${ }^{2}$ and is related to the normal contact force via a kinetic friction coefficient, $\mu_{k}$ (which is typically less than its static counterpart). ${ }^{2}$ For conditions of lubricated sliding or viscous friction, the friction force is proportional to the sliding velocity, $v$, according to Stokes' law (first proposed by George Stokes in $1851^{3}$ ):

$$
F=\gamma v=\frac{M}{\tau} v,
$$

where $\gamma$ is a damping constant, $M$ is the total mass of the sliding object, and $\tau$ is the slip time. Note that no force is needed to initiate sliding under viscous friction (i.e., $v=0$, $F=0$ ). The validity of Stokes' friction law has been confirmed for lubricant monolayers and continuum-scale fluid films. ${ }^{4}$ Neither macroscopic friction law explicitly incorporates the effects of sliding material chemistry and interfacial geometry on friction.

Dry sliding friction remains an especially active area of research due in part to interest in the ubiquitous stick-slip phenomenon, new insights into microscopic-scale friction, and friction associated with seismic dynamics. Stick-slip behavior (or tangential oscillation in sliding contacts) results from one of three causes: the inequality of static and kinetic friction coefficients (i.e., $\mu_{s} \neq \mu_{k}$ ); a decrease in $\mu_{k}$ with increasing sliding velocity; and fluctuations in friction along a contact. $^{5} \mathrm{~A}$ truly remarkable aspect of stick-slip is its prevalence in myriad chemical and physical processes that span a broad range of length scales. ${ }^{6}$ Some examples are the unzip- ping of DNA strands $;{ }^{7}$ serrated yielding in metals; ${ }^{8}$ the bowstring interaction in orchestral instruments $;{ }^{9}$ curve squeal in rail wheels: ${ }^{10}$ and sliding between faults during an earthquake. ${ }^{11}$

Considerable insight into the validity of macroscale friction laws at the atomic and nanometric scales (which we collectively refer to as the "microscopic" scales), and characteristic features of dry sliding friction, such as stick-slip, has resulted from the development of new surface measurement instrumentation. Examples of this new class of instruments are the scanning tunneling microscope,${ }^{12}$ the atomic force microscope $(\mathrm{AFM})^{13}$ and its scanning probe variants, the surface force apparatus (SFA), ${ }^{14}$ and the quartz-crystal microbalance $(\mathrm{QCM}) .{ }^{15}$ Recent experiments suggest that dry sliding friction at microscopic scales does not always behave according to Coulomb's law, thereby suggesting the need for new laws that account for atomic scale phenomena. For example, Krim et al. ${ }^{16}$ reported QCM measurements of the friction of krypton monolayers sliding on gold. The solid monolayer exhibited a viscous force law. Using a friction force microscope, Zwörner et al. ${ }^{17}$ found that the friction forces between silicon tips and different carbon compounds were constant over a wide range of sliding velocities. Gnecco et al. ${ }^{18}$ reported a logarithmic dependence of the friction force at low velocity for a silicon tip sliding on a $\mathrm{NaCl}(100)$ surface. Schmid and Hector ${ }^{19}$ observed stick-slip behavior during abrasive wear experiments on aluminum alloy substrates. The plowing motion of a pyramidal diamond indenter (with a nanometric-scale tip radius) was controlled with the piezoelectric transducers in an AFM. They found that the frequency of stick-slip patterns in the resulting plow tracks largely depends upon alloying agent chemistry.

Not surprisingly, the growth of experimental work on microscopic-scale friction has stimulated interest in the theoretical community. ${ }^{20,21}$ For example, simulation tools such 
as molecular dynamics (MD) with semiempirical force fields have been used to help understand the effect of cantilever spring constants and surface atom dynamics in AFM-based sliding experiments. ${ }^{22}$ Alternatively, measurement of the complicated behavior of friction at microscopic scales can depend upon the properties of the measuring system. For example, kinetic friction coefficients are difficult to measure due to stick-slip motion and can depend upon the dynamics of the measuring system. ${ }^{9}$ This suggests that theoretical treatments of microscopic-scale friction using MD may be useful for revealing friction behavior that cannot otherwise be decoupled from the measuring instrument. Although it may seem that theoretical work has blossomed only recently (for example, see Refs. 23-29 and 35) in light of algorithmic and computer hardware advancements, an early theoretical treatment of atomic scale friction was reported by Tomlinson in 1929 who suggested that energy dissipation in sliding friction is due to lattice vibrations. ${ }^{23}$ Tomlinson's work was recently extended by Gnecco et al. ${ }^{24}$ to interpret the logarithmic velocity dependence noted in Ref. 18. With MD simulations, Smith et al. ${ }^{4}$ verified Krim's ${ }^{16}$ experimental results assuming that friction was due to phonons excited in adsorbed layers and follows a viscous law. Some theoretical models have been used to interpret the origin of Coulomb friction due to a multistability mechanism. ${ }^{25,26}$ Before sliding, atoms are trapped in a metastable state. As a sliding body moves, the state becomes unstable and the atoms "pop" to the next metastable state (hence the term "multistability" is applied to describe the atom states). The atom velocity, $v_{j}$, is much higher than, and independent of, the sliding speed $v$. Therefore kinetic friction is due to the energy dissipated via $v_{j}$ and independent of the sliding speed. Although sudden "pops" have been observed in some sliding samples with boundary lubricants, this mechanism is probably not responsible for the unique properties of microscopic-scale kinetic friction in dry sliding. ${ }^{25,26} \mathrm{Li}$ et al. investigated sliding at an atomic-scale $\mathrm{Ni}-\mathrm{Al}$ interface using $\mathrm{MD}$ and concluded that stick-slip is due to elastic deformation of surface layers. ${ }^{27}$

A geometrical feature of interfaces that plays an important role in atomic scale friction is interfacial commensuration or orientation. Experimental studies ${ }^{30,31}$ have in fact shown that with incommensurate contact (e.g., where the surfaces are rotated through a small angle $\theta$ relative to one-another), the kinetic friction force is very small compared with that for a commensurate interface (i.e., where both surfaces are aligned). This is supported by the notion of superlubricity (i.e., zero frictional force), which has been observed in mica, silicon, graphite, and other materials in flat incommensurate contact under dry conditions. ${ }^{32-34} \mathrm{He}$ et al. and Muser and Robbins used a simple bead-spring model with a LeonardJones potential to simulate the behavior of hydrocarbon films confined between two stiff atomic walls. ${ }^{25}$ They concluded that nonvanishing static friction at an incommensurate interface results from molecular interlocking of the two surfaces following rearrangement of the molecules. Qi et al. showed that atomic-scale surface roughness can dramatically increase static friction at incommensurate $\mathrm{Ni}(100) / \mathrm{Ni}(100)$ interfaces ${ }^{35}$ However, the manner in which atomic-scale surface roughness affects kinetic friction during dry sliding remains unclear. Although the role of interface commensura- tion on static friction has been investigated, ${ }^{35}$ there is currently a dearth of information regarding the role of interface commensuration on microscopic-scale kinetic friction.

In this work, we used MD to compute kinetic friction during dry sliding along atomistic-scale $\mathrm{Al}(001) / \mathrm{Al}(001)$ and $\alpha-\mathrm{Al}_{2} \mathrm{O}_{3}(0001) / \alpha-\mathrm{Al}_{2} \mathrm{O}_{3}(0001)$ interfaces ("interfaces" is the assumed designation for each system and will be dropped from here on) over a wide range of sliding speeds. In addition to their technological relevance, these interfaces represent two different material classes, i.e., metals and ceramics, with differing bond characters that are likely to play an important role in microscopic-scale friction. Although experimental sliding and indentation data for single crystal $\mathrm{Al}$ and $\mathrm{Al}_{2} \mathrm{O}_{3}$ in vacuum exist, ${ }^{36-38}$ there appears to be no velocity-dependent kinetic friction data: this provided motivation for the theoretical models and associated analysis in this paper. Our simulation methodology combined MD with recently developed Reactive Force Fields (ReaxFF). We were particularly interested in determining if kinetic friction variations predicted with MD follow the macroscopic-scale friction laws, i.e., Coulomb's law (for dry sliding) and Stokes' friction law (for lubricated sliding): this required that we examine friction over a range of sliding velocities. Models of both commensurate and incommensurate $\alpha-\mathrm{Al}_{2} \mathrm{O}_{3}(0001) / \alpha-\mathrm{Al}_{2} \mathrm{O}_{3}(0001)$ and atomically smooth and rough incommensurate $\mathrm{Al}(001) / \mathrm{Al}(001)$ were constructed. We were also interested in exploring those conditions where stick-slip appears, as well as those conditions where it does not appear for the different material chemistries. The roles of the static potential (due to interfacial adhesion without continuous sliding), the release of stored strain energy in the sliding materials, and thermal phonon damping were explored for each sliding couple: the latter two mechanisms manifest themselves within specific ranges of sliding velocity. It is important to note that the interfaces we constructed were sufficiently small (i.e., about 1000 atoms) as to minimize defect formation and prevent material mixing during MD simulation, and hence allowed us to focus on interfacial friction due primarily to differences in the material chemistries, interfacial commensuration, and surface roughness. This, and the application of the reactive force fields, differentiates our work from existing large-scale (i.e., tens-ofthousands of atoms) MD simulation on dry sliding friction in crystalline and amorphous metal systems wherein the velocity dependence of friction was largely controlled by factors other than those we wished to explore in the present paper. ${ }^{39-41}$

The remainder of this paper is organized as follows: in Sec. II we briefly review the force fields that are used in our MD simulations; in Sec. III we describe our interface models; the MD simulations are discussed in Sec. IV; our simulation results are discussed in Sec. V; and the results of the work are summarized in Sec. VI.

\section{REACTIVE FORCE FIELDS}

The MD simulations in the present work incorporated the recently developed Reactive Force Fields (ReaxFF) for $\alpha-\mathrm{Al}_{2} \mathrm{O}_{3}$ and $\mathrm{Al}^{42}{ }^{42}$ The ReaxFF formalism represents a sig- 


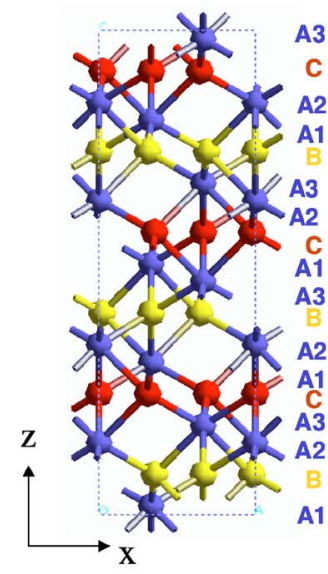

(a)

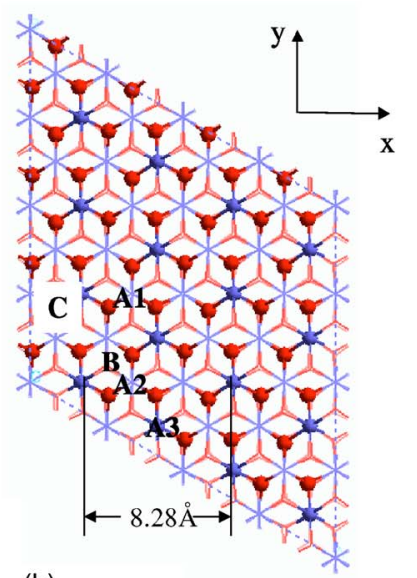

(b)

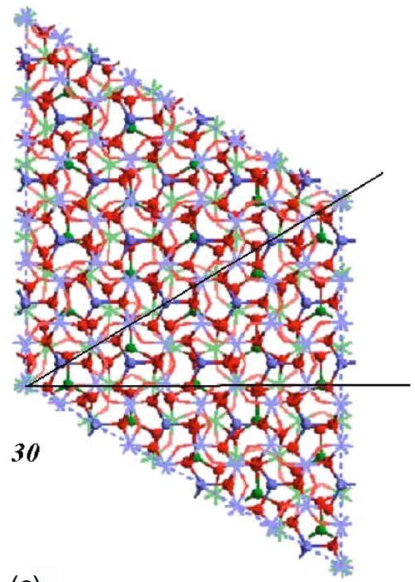

(c)

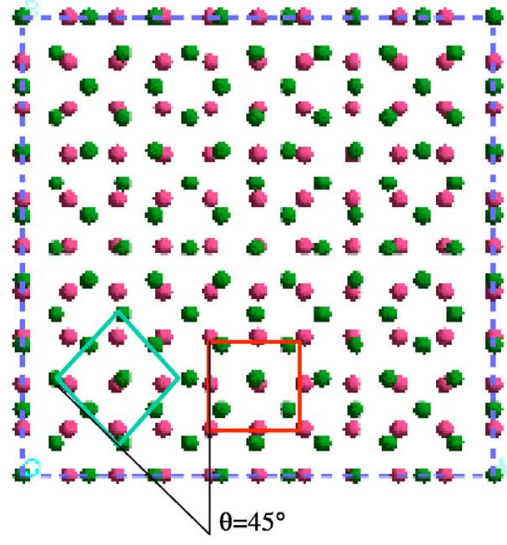

(d)

FIG. 1. (Color online) (a) Sideview of crystalline $\alpha-\mathrm{Al}_{2} \mathrm{O}_{3}$. (b) Surface of $\alpha-\mathrm{Al}_{2} \mathrm{O}_{3}(0001)$ : Blue: Al, Red: O. Only one layer of $\mathrm{Al}$ atoms (A1 position) and one layer of $\mathrm{O}$ atoms (B position) are shown; $\mathrm{A} 2$ and $\mathrm{A} 3$ positions for $\mathrm{Al}$ atoms are marked. (c) Incommensurate $\alpha-\mathrm{Al}_{2} \mathrm{O}_{3}(0001) / \alpha-\mathrm{Al}_{2} \mathrm{O}_{3}(0001)$ : red: $\mathrm{O}$, green: $\mathrm{Al}$ in bottom layer, and blue: $\mathrm{Al}$ in top layer. (d) Incommensurate $\mathrm{Al}(001) / \mathrm{Al}(001)$.

nificant improvement over earlier force fields in that it accurately simulates chemical reactivity (e.g., bond formation, bond breaking) and charge transfer, while including Coulomb and van der Waals interactions (see Ref. 43 for an overview of the method applied to small molecules). Each of the parameters in the ReaxFF was developed solely with $a b$ initio quantum mechanical calculations on various phases of $\mathrm{Al}, \alpha-\mathrm{Al}_{2} \mathrm{O}_{3}$, and $\mathrm{Al}-\mathrm{O}-\mathrm{H}$ clusters. The ReaxFF accurately reproduces the charge, lattice constants, elastic constants, surface energies, and equation-of-state for crystalline $\mathrm{Al}$ and $\alpha-\mathrm{Al}_{2} \mathrm{O}_{3}$. It has recently been used to study both solid and liquid $\mathrm{Al} / \alpha-\mathrm{Al}_{2} \mathrm{O}_{3}$ interfaces ${ }^{42}$ wherein the calculated work of separation for the solid-solid interface was found to closely agree with earlier first principles calculations and experiments. For the liquid-Al-on-solid- $\alpha-\mathrm{Al}_{2} \mathrm{O}_{3}(0001)$ system, the predicted nonwetting-wetting transition temperature was in good agreement with sessile drop experiments. Another important feature of ReaxFF is that the parameters of each element are fully transferable, which means that the parameters for $\mathrm{Al}$ in metallically bonded $\mathrm{Al}$ metal are the same as those in ionically bonded $\alpha-\mathrm{Al}_{2} \mathrm{O}_{3}$. It is therefore appropriate to employ the associated ReaxFF to investigate sliding friction at $\mathrm{Al}(001) / \mathrm{Al}(001)$ and $\alpha-\mathrm{Al}_{2} \mathrm{O}_{3}(0001) / \alpha-\mathrm{Al}_{2} \mathrm{O}_{3}(0001)$. The ReaxFF technique has also been used to simulate properties of crystalline $\mathrm{Si}, \mathrm{SiO}_{2}$, and $\mathrm{Si} / \mathrm{SiO}_{2}$ interfaces. ${ }^{44}$

\section{INTERFACE MODELS}

\section{A. $\alpha-\mathrm{Al}_{2} \mathrm{O}_{3}(0001) / \alpha-\mathrm{Al}_{2} \mathrm{O}_{3}(0001)$}

The hexagonal unit cell of the corundum structure, which has the $R \overline{3} c$ space group, contains 30 atoms or $6-\alpha-\mathrm{Al}_{2} \mathrm{O}_{3}$ molecular units. ${ }^{45}$ Bonding is primarily ionic with a small degree of covalency. ${ }^{46}$ The lattice is arranged with oxygen atoms in a hexagonal close-packed array with the BCBC stacking sequence, as shown in Fig. 1(a). Between the successive oxygen layers there are two Al layers with $\mathrm{Al}$ atoms occupying one-third of the octahedral interstitial sites in each layer, [labeled A1, A2, and A3 in Fig. 1(a)]. The Al and O layer stacking sequence along the $c$-direction of the $\alpha-\mathrm{Al}_{2} \mathrm{O}_{3}$ hexagonal unit cell can be written as $\mathrm{Al}(\mathrm{A} 1)-\mathrm{O}(\mathrm{B})$ $\mathrm{Al}(\mathrm{A} 2)-\mathrm{Al}(\mathrm{A} 3)-\mathrm{O}(\mathrm{C})-\mathrm{Al}(\mathrm{A} 1)-\mathrm{Al}(\mathrm{A} 2)-\mathrm{O}(\mathrm{B})-\mathrm{Al}(\mathrm{A} 3)-\mathrm{Al}(\mathrm{A} 1)-$ $\mathrm{O}(\mathrm{C})-\mathrm{Al}(\mathrm{A} 2)-\mathrm{Al}(\mathrm{A} 3)-\mathrm{O}(\mathrm{B})-\mathrm{Al}(\mathrm{A} 1)-\mathrm{Al}(\mathrm{A} 2)-\mathrm{O}(\mathrm{C})-\mathrm{Al}(\mathrm{A} 3)$.

From experiments and $a b$ initio calculations, ${ }^{47,48}$ the single layer, Al-terminated $\alpha-\mathrm{Al}_{2} \mathrm{O}_{3}(0001)$ surface (which is stoichiometric) is the most energetically stable surface of clean $\alpha-\mathrm{Al}_{2} \mathrm{O}_{3}(0001)$. Construction of Al-terminated $\alpha-\mathrm{Al}_{2} \mathrm{O}_{3}(0001) / \alpha-\mathrm{Al}_{2} \mathrm{O}_{3}(0001)$ required that we consider two interfacial stacking sequences, viz., A1/A1 and A1/A3. Since the A1/A3 stacking sequence will lead to collapse of the two slabs into a single crystal, we built our interface following the A1/A1 stacking sequence, in which Al surface atoms in the top slab lie atop $\mathrm{Al}$ surface atoms in the bottom slab. We note that aluminum oxide surfaces are typically hydroxylated (MD studies of hydroxylated aluminum surfaces have been reported in Refs. 49 and 50) and contain alloying agents and components of other oxide structures. ${ }^{45}$ However, we elected to simulate conditions where passivating layers are removed, a condition that is likely under dry or underlubricated sliding conditions. We also assumed that no alloying agents or transition oxides (e.g., $\gamma-\mathrm{Al}_{2} \mathrm{O}_{3}$ ) are present in the corundum slabs. ${ }^{45}$

Each slab in our fully commensurate interface was constructed as a $4 a \times 4 a \times c$ superlattice with 480 atoms, where $a$ and $c$ are $\alpha-\mathrm{Al}_{2} \mathrm{O}_{3}$ lattice constants, with $a=4.78 \AA$ and $c=13.25 \AA$. The lattice constants were determined from an equation-of-state calculation at $0 \mathrm{~K} .{ }^{42}$ The cell consisted of $284 \mathrm{Al}$ and $576 \mathrm{O}$ atoms, giving a 960-atom interface. In Fig. 1 (b), we show a top view [i.e., looking along (0001)] of an $\alpha-\mathrm{Al}_{2} \mathrm{O}_{3}(0001)$ slab with the $\mathrm{O}$ and terminal $\mathrm{Al}$ layers shown by red and blue spheres, respectively. Note that the periodic distance along the $x$ direction between adjacent terminal $\mathrm{Al}$ atoms is $8.28 \AA$ as indicated in the figure.

Prior to the MD simulations, the as-cleaved $\alpha-\mathrm{Al}_{2} \mathrm{O}_{3}(0001)$ slabs were minimized at $0 \mathrm{~K}$. They were then brought into contact to form a sliding pair in a single cell that is periodic in the $x$ and $y$ directions with a large enough vacuum distance along the $z$ direction to simulate 
slabs of infinite lateral extent. The initial interfacial separation was determined through a set of single point energy calculations as a function of interface distance, and the equilibrium interfacial separation was determined at the minimum energy position, which is about $2.5 \AA$. We then equilibrated each interface at $300 \mathrm{~K}$. In the friction simulations, we chose the $x$ direction as the sliding direction (for convenience): for the commensurate interface, this is along [1010] for both slabs. Each $\alpha-\mathrm{Al}_{2} \mathrm{O}_{3}(0001) / \alpha-\mathrm{Al}_{2} \mathrm{O}_{3}(0001)$ was atomically smooth, i.e., we did not remove (or add) any atoms from the interface region.

The incommensurate interface, which is shown along (0001) in Fig. 1(c), was constructed by rotating the top slab (with the $\mathrm{Al}$ atoms in blue) through $30^{\circ}$ (denoted with the two solid lines in the figure) relative to the bottom slab (with $\mathrm{Al}$ atoms in green), following the hexagonal symmetry: this is the largest misorientation angle between the two surfaces. The sliding direction remains along $x$, which is [1010] for the bottom slab and [112̄0] for the top slab. To minimize lattice mismatch, we chose $5 a \times 5 a \times c$ for the bottom slab (750 atoms) and $3 \sqrt{ } 3 a \times 3 \sqrt{ } 3 a \times c$ for the top slab (810 atoms), leading to a lattice mismatch of $3.8 \%$, which will not significantly impact our results. We took the cell lengths along $x$ and $y$ for the top slab and slightly strained the bottom slab to build the interface structure.

\section{B. $\operatorname{Al}(001) / \operatorname{Al}(001)$}

We constructed incommensurate $\mathrm{Al}(001) / \mathrm{Al}(001)$ since the corresponding commensurate interface collapses into a single crystal. Therefore the [110] axis of the top surface was set to match the [100] direction of the bottom surface, leading to a $\theta=45^{\circ}$ mismatch angle. This is shown in Fig. 1(d), where the atoms of the top slab are red and the green atoms belong to the bottom slab. The bottom slab is a $5 a \times 5 a \times 4 a$ superlattice with $400 \mathrm{Al}$ atoms, and the top slab is a $7 / \sqrt{ } 2 a \times 7 / \sqrt{ } 2 a \times 4 a$ superlattice with $392 \mathrm{Al}$ atoms. Each slab consists of eight layers of (001) planes and the lattice mismatch is about $1 \%$. In addition to the atomically smooth interface, we also constructed a rough interface by randomly deleting about $15 \%$ of the atoms in the two interfacial layers. There were altogether 15 atoms that were deleted from the interface layers, which gave a rms roughness of about $0.6 \AA$ at the interface. The $x$ direction, which is [100] for the bottom slab and [110] for top slab, is again the sliding direction. The $\mathrm{Al}(001) / \mathrm{Al}(001)$ interfaces were equilibrated at $300 \mathrm{~K}$.

\section{MOLECULAR DYNAMICS SIMULATIONS}

Molecular dynamics simulations were carried out on each equilibrated interface using the constant volume constant energy (NVE) conditions at an initial temperature of $300 \mathrm{~K}$. Figure 2 shows the equilibrated $\alpha-\mathrm{Al}_{2} \mathrm{O}_{3}(0001) /$ $\alpha-\mathrm{Al}_{2} \mathrm{O}_{3}(0001)$ (commensurate) interface structure with which we began the MD simulations. Note that the terminal $\mathrm{Al}$ atoms relax into their respective slabs: this is consistent with $a b$ initio predictions. ${ }^{46}$ Sliding friction was generated by

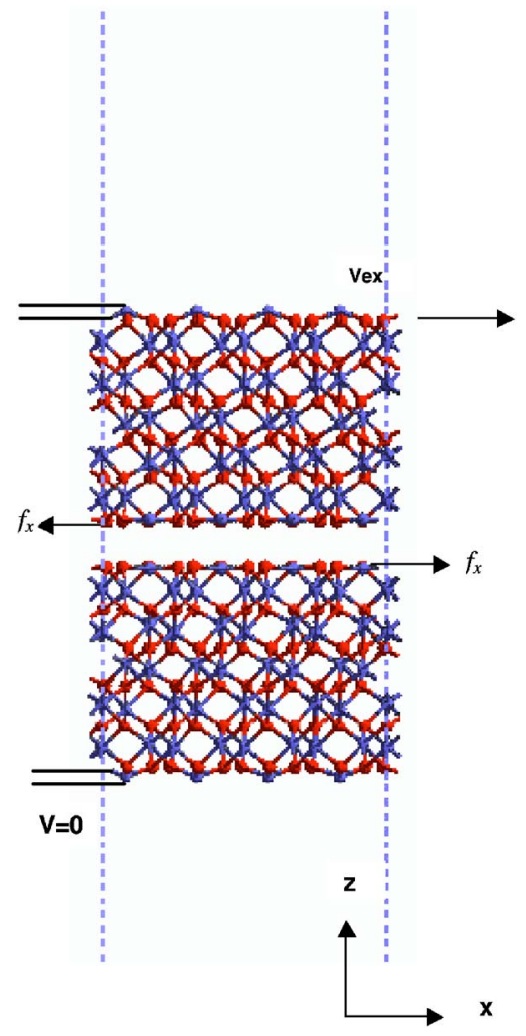

FIG. 2. (Color online) Equilibrated $\alpha-\mathrm{Al}_{2} \mathrm{O}_{3}(0001) /$ $\alpha-\mathrm{Al}_{2} \mathrm{O}_{3}(0001)$ (commensurate) used in the constant velocity sliding simulations. (The length of the $z$ direction is fixed, so the slabs are under compression.)

forcing the top slab to slide over the bottom slab via the constant velocity method (CVM). Unlike other MD simulations of sliding friction, wherein a force is applied to cause sliding ${ }^{27}$ (which is more appropriate for static friction calculations), use of the CVM in the present simulations allowed us to calculate kinetic friction at a fixed sliding velocity. In the CVM, an external velocity, $V_{\mathrm{ex}}$, is added to the thermal velocity of each atom in the outmost layers of the top slab at each time step, while the atoms in the outermost layers of the bottom slab are constrained from moving in the $x$ direction [in all of our simulations outmost layers refer to $1 \mathrm{Al}$ layer $+1 \mathrm{O}$ layer in $\alpha-\mathrm{Al}_{2} \mathrm{O}_{3}(0001)$, and $1 \mathrm{Al}$ layer in $\mathrm{Al}(111)$ ]. The movement of the outmost layers in the top slab is transmitted to the entire slab very quickly (i.e., in under $0.1 \mathrm{ps}$ ); therefore the top slab will immediately slide with the applied sliding velocity, $V_{\mathrm{ex}}$. This is different from Li's ${ }^{27}$ model, for example, wherein an external force close to the static friction force was applied to the central atoms in the upper slab. In the CVM, the top slab is moving at a constant velocity; therefore the frictional force at the interface must be balanced by an external applied force that results from $V_{\mathrm{ex}}$. In our simulations, the kinetic friction force is the sum of the lateral atomic forces for all atoms in the upper slab along the sliding direction (see Fig. 2). During sliding, the $z$-direction movement of the atoms in the outmost layers of each slab is fixed to mimic a normal loading condition. The normal forces in the slabs are therefore repulsive. Simulation times for each $V_{\text {ex }}$ were in the 140-200 ps range. This range was 
deemed sufficient since thermodynamic properties, such as total energy, temperature, pressure, etc., become steady after the first 20 ps. It should be noted that we saw no evidence of melting in any of the simulations.

\section{MD SIMULATION RESULTS AND DISCUSSION}

\section{A. Kinetic friction at $\alpha-\mathrm{Al}_{2} \mathrm{O}_{3}(0001) / \alpha-\mathrm{Al}_{2} \mathrm{O}_{3}(0001)$}

Molecular dynamics sliding simulations of $\alpha-\mathrm{Al}_{2} \mathrm{O}_{3}(0001) / \alpha-\mathrm{Al}_{2} \mathrm{O}_{3}(0001)$ were conducted for $V_{\mathrm{ex}}=10-400 \mathrm{~m} / \mathrm{s}$. We first examined the potential energy of the interface couple, $U(x)$ (which is the sum of the slab energies and the interfacial energy), as a function of sliding distance for a given $V_{\mathrm{ex}}$. Note that the shape of $U(x)$ highlights important chemical and physical phenomena of microscopic-scale sliding that affect kinetic friction at a given $V_{\text {ex }}$. Since the energy of the two slabs can be treated as constant during sliding, the spatial rate of change of $U(x)$ along the sliding direction is the corresponding spatial change in interfacial energy or the instantaneous kinetic friction force. We define the sliding distance as the instantaneous difference between the $x$-positions of the centers of mass of the top and bottom slabs. The zero displacement reference between the centers of mass of the two slabs is the starting point for sliding. In each sliding MD simulation, the sliding velocity is fixed at $V_{\text {ex }}$; therefore the time rate of change of the sliding distance is fixed. Figure 3(a) shows the variation of $U(x)$, (in $\mathrm{kcal} / \mathrm{mol}$ ) with sliding distance in $\AA$ due to $V_{\mathrm{ex}}=10 \mathrm{~m} / \mathrm{s}, \quad 30 \mathrm{~m} / \mathrm{s}$ for commensurate $\alpha-\mathrm{Al}_{2} \mathrm{O}_{3}(0001) /$ $\alpha-\mathrm{Al}_{2} \mathrm{O}_{3}(0001)$. The computed $U(x)$ at $V_{\text {ex }}=100 \mathrm{~m} / \mathrm{s}$, $200 \mathrm{~m} / \mathrm{s}$ for commensurate $\alpha-\mathrm{Al}_{2} \mathrm{O}_{3}(0001) / \alpha-\mathrm{Al}_{2} \mathrm{O}_{3}(0001)$ is shown in Fig. 3(b). The static potential energy profile $U_{0}(x)$ (which is appropriate for $V_{\mathrm{ex}}=0$ with no temperature or velocity effects) along the sliding direction is also displayed in Figs. 3(a) and 3(b). Note that $U_{0}(x)$ represents the potential energy due to interfacial bonding or adhesion in the absence of continuous sliding: differences between $U_{0}(x)$ and $U(x)$ result from sliding at $V_{\mathrm{ex}}$. The $U_{0}(x)$ curves were generated by first shifting the top slab relative to the bottom slab at an increment of $0.2 \AA$ along the sliding direction, followed by minimization of the potential energy at each shifted configuration. This process was continued in a stepwise fashion over a total sliding distance of $20 \AA$. It is clear from Fig. 3(a) that $U(x)$ changes in accordance with the periodic potential of the slabs during sliding. A long-range periodicity is evident in all three potential curves, although the curves for $V_{\mathrm{ex}}=10,30 \mathrm{~m} / \mathrm{s}$ shown in Fig. 3(a) display some small high frequency fluctuations. The system moves from an absolute maximum (i.e., a hill) in $U(x)$ to an absolute minimum (i.e., a well) every $8.28 \AA$ (i.e., the repeat distance between two terminal $\mathrm{Al}$ atoms along $x$ shown in Fig. 1(b)). Little change in $U(x)$ for commensurate $\alpha-\mathrm{Al}_{2} \mathrm{O}_{3}(0001)$ / $\alpha-\mathrm{Al}_{2} \mathrm{O}_{3}(0001)$ was noted for $V_{\mathrm{ex}} \leqslant 60 \mathrm{~m} / \mathrm{s}$. The inset figure in Fig. 3(a) shows a magnified view of how the slope of $U(x)$ changes with sliding distance. Significant variation in $U(x)$ above $U_{0}(x)$ was not noted until $V_{\mathrm{ex}}=100 \mathrm{~m} / \mathrm{s}$, as shown in Fig. 3(b). For $V_{\mathrm{ex}}=200 \mathrm{~m} / \mathrm{s}$, the periodicity in $U(x)$ diminishes and the peak to valley excursions increase since con-
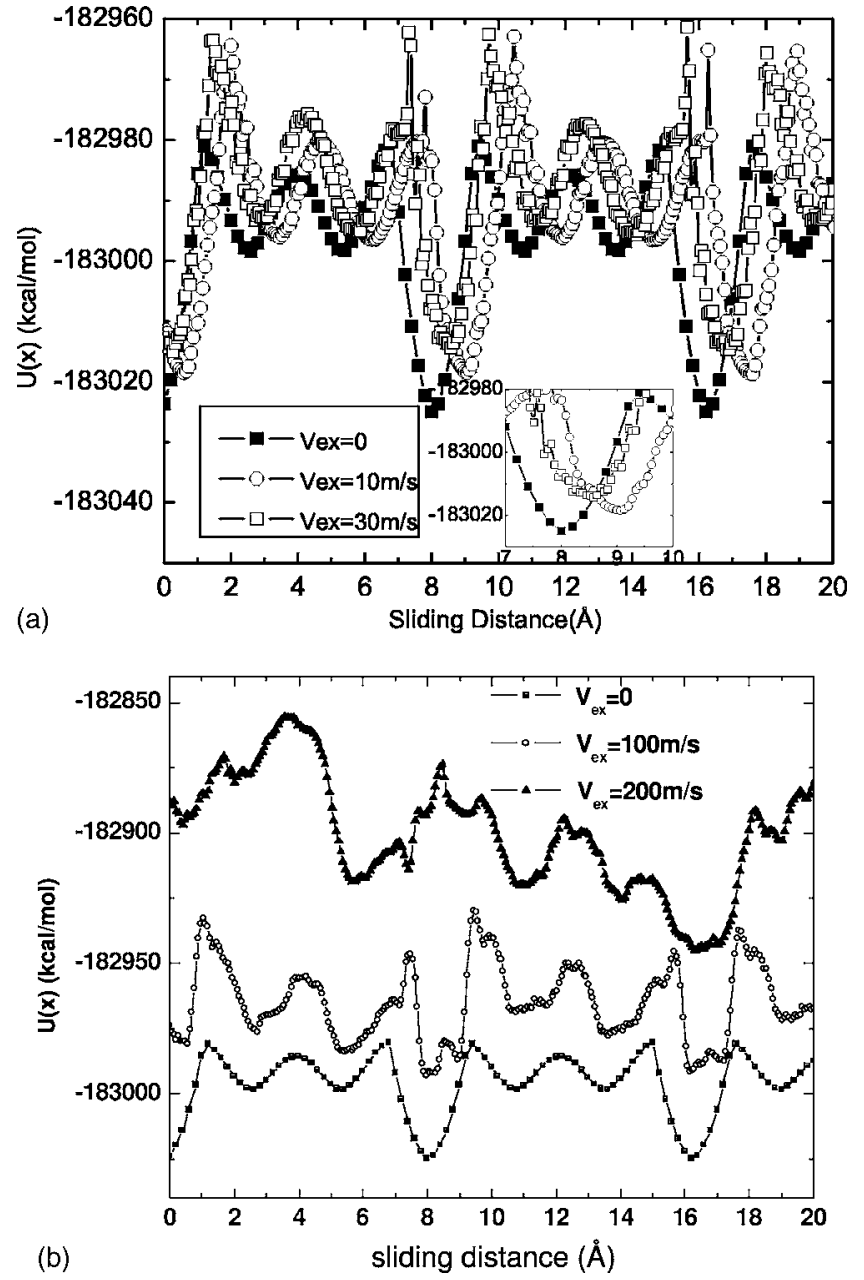

FIG. 3. Potential energy, $U(x)$, vs sliding distance for commensurate $\alpha-\mathrm{Al}_{2} \mathrm{O}_{3}(0001) / \alpha-\mathrm{Al}_{2} \mathrm{O}_{3}(0001)$ : (a) with $V_{\mathrm{ex}}=10,30 \mathrm{~m} / \mathrm{s}$; (b) with $V_{\mathrm{ex}}=100,200 \mathrm{~m} / \mathrm{s}$. For the static potential energy, $U_{0}(x)$, $V_{\mathrm{ex}}=0$.

tributions from thermal phonons become more prevalent at these higher velocities. In addition, atomic relaxation effects also contribute to the diminishing periodicity in $U(x)$. As the sliding velocity is increased, there is less time for the interface to undergo the atomic rearrangements necessary to reach the minimum energy configuration. Compared with the static case, the potential energy wells for the $V_{\mathrm{ex}}=100 \mathrm{~m} / \mathrm{s}$, $200 \mathrm{~m} / \mathrm{s}$ curves in Fig. 3(b) become shallower and the energy hills become higher.

To facilitate comparison between friction at interfaces with different contact areas [for example, the surface areas of $\alpha-\mathrm{Al}_{2} \mathrm{O}_{3}(0001)$ and $\mathrm{Al}(111)$ differ], we define a friction force per contact area, $f_{x}$, which represents the intensity of the friction force. Note that we extracted $f_{x}$ directly from the MD calculations since it is the total lateral atomic force on the upper slab divided by the contact area at each MD time step during sliding. Hence $f_{x}$ is the sum of all atomic forces along the $x$ direction. Since the internal forces cancel, only those lateral forces at the interface remain. Alternatively, $f_{x}$ can be computed from 

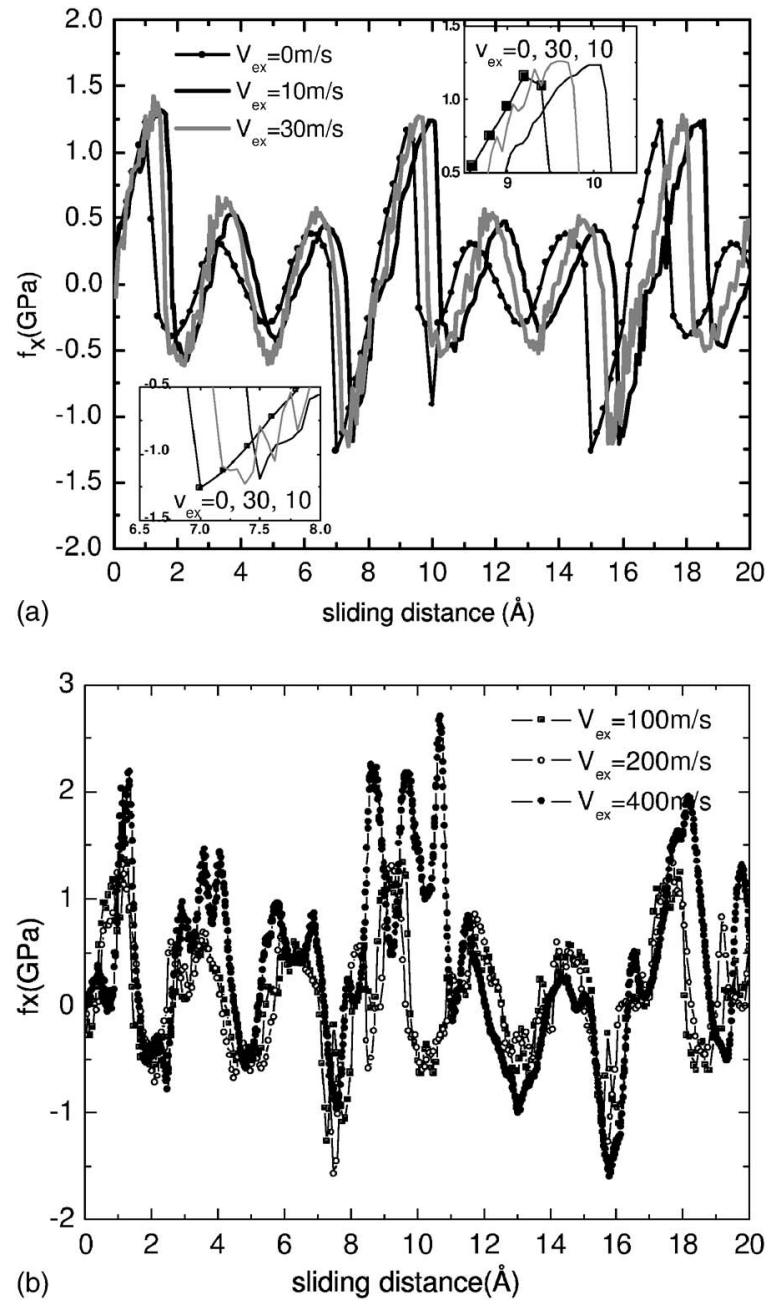

FIG. 4. Instantaneous kinetic frictional force, $f_{x}$, as a function of sliding distance for commensurate $\alpha-\mathrm{Al}_{2} \mathrm{O}_{3}(0001) / \alpha-\mathrm{Al}_{2} \mathrm{O}_{3}(0001)$. (a) $V_{\text {ex }}=0,10,30 \mathrm{~m} / \mathrm{s}$; (b) $V_{\text {ex }}=100,200,400 \mathrm{~m} / \mathrm{s}$.

$$
f_{x}=\frac{1}{A} \frac{d U(x)}{d x}
$$

which we verified through a comparison with our directly computed $f_{x}$. Figure 4 shows $f_{x}$ as a function of sliding distance at different $V_{\text {ex }}$ for commensurate $\alpha$ - $\mathrm{Al}_{2} \mathrm{O}_{3}(0001) /$ $\alpha-\mathrm{Al}_{2} \mathrm{O}_{3}(0001)$. We also calculated $d U_{0}(x) / d x$, which is the force needed to overcome the energy barriers in $U_{0}(x)$ shown in Fig. 3. Recall that the force due to the static potential energy, i.e., $d U_{0}(x) / d x$, is actually due to the interfacial energy change. The significance of $d U_{0}(x) / d x$ is that it provides a lower bound on the instantaneous kinetic frictional force, $f_{x}$, during low velocity sliding. A maximum lateral force, $f_{0}^{\max }$, can be defined as

$$
f_{0}^{\max }=\frac{1}{A} \max \left(\frac{d U_{0}(x)}{d x}\right) .
$$

Table I lists the values for $f_{0}^{\max }$ computed from Eq. (3) for interfaces considered in this work. Note that $f_{0}^{\max }$ for commensurate $\alpha-\mathrm{Al}_{2} \mathrm{O}_{3}(0001) / \alpha-\mathrm{Al}_{2} \mathrm{O}_{3}(0001)$ is more than twice that of the incommensurate interface. Figure 4(a) also dis-
TABLE I. Computed maximum lateral forces, $f_{0}^{\max }$, calculated from $d U_{0}(x) / d x$.

\begin{tabular}{lc}
\hline \hline \multicolumn{1}{c}{ Interface } & $f_{0}^{\max }(\mathrm{GPa})$ \\
\hline Commensurate $\alpha-\mathrm{Al}_{2} \mathrm{O}_{3}(0001) / \alpha-\mathrm{Al}_{2} \mathrm{O}_{3}(0001)$ & 1.3 \\
Incommensurate $\alpha-\mathrm{Al}_{2} \mathrm{O}_{3}(0001) / \alpha-\mathrm{Al}_{2} \mathrm{O}_{3}(0001)$ & 0.4 \\
Incommensurate (smooth) $\mathrm{Al}(001) / \mathrm{Al}(001)$ & 0.002 \\
Incommensurate (rough) $\mathrm{Al}(001) / \mathrm{Al}(001)$ & 0.4 \\
\hline \hline
\end{tabular}

plays $f_{0}^{\max }$ for comparison with $f_{x}$ resulting from selected values of $V_{\text {ex }}$. For the lower velocities in Fig. 4(a) (i.e., 10 and $30 \mathrm{~m} / \mathrm{s}$ ), the lateral force exhibits intermittent motion typical of "stick-slip." The "stick-slip" periodicity is about $8.28 \AA$ and it is virtually independent of $V_{\mathrm{ex}}$ since the curves corresponding to the two nonzero values of $V_{\mathrm{ex}}$ are almost on top of the $d U_{0}(x) / d x$ curve. Figure 4(b) shows that as $V_{\mathrm{ex}}$ is increased beyond $100 \mathrm{~m} / \mathrm{s}$, the corresponding $f_{x}$ curves noticeably deviate from $V_{\text {ex }}=0$. The $f_{x}$ curves still exhibit peaks and valleys for $V_{\text {ex }}>200 \mathrm{~m} / \mathrm{s}$, but stick-slip behavior is less obvious due to fluctuations from thermal phonons and less time for the system to reach an equilibrium state. The inset figures in Fig. 4(a) show that at low velocity, the minimum forces (or slip forces) at finite velocities are all larger than that for $V_{\mathrm{ex}}=0$, and the maximum forces (or stick forces) are all larger than that for $V_{\mathrm{ex}}=0$. But the minimum force decreases, while the maximum force remains almost the same in going from $V_{\mathrm{ex}}=10 \mathrm{~m} / \mathrm{s}$ to $V_{\mathrm{ex}}=30 \mathrm{~m} / \mathrm{s}$. However, this behavior is reversed at high velocities. As shown in Fig. 4(b), the maximum force increases with increasing velocity while the minimum force remains almost the same in going from $V_{\text {ex }}=100 \mathrm{~m} / \mathrm{s}$ to $V_{\text {ex }}=400 \mathrm{~m} / \mathrm{s}$.

The forces due to the static interfacial interaction, $d U_{0}(x) / d x$, can cause the slab to store strain energy through shearing during the stick phase. The strain energy is released once slip occurs. To investigate the extent of shearing in $\alpha-\mathrm{Al}_{2} \mathrm{O}_{3}(0001) / \alpha-\mathrm{Al}_{2} \mathrm{O}_{3}(0001)$, we calculated the position of the center of mass of the outmost layer (1 Al layer+1 O layer), $X_{t}$, and that for the interface layer (1 Al layer +1 O layer), $X_{i}$, respectively. The shear distance between the outmost layer and the interface layer, $\Delta X=\left(X_{t}-X_{i}\right)$, is proportional to the shear strain, which is the shear distance divided by the thickness of the upper slab. Without shearing, $\Delta X$ should remain unchanged during sliding. The closed and open circles in Fig. 5(a) display the variation of $\Delta X$ with sliding distance for commensurate and incommensurate $\alpha-\mathrm{Al}_{2} \mathrm{O}_{3}(0001) / \alpha-\mathrm{Al}_{2} \mathrm{O}_{3}(0001)$ due to $V_{\text {ex }}=10 \mathrm{~m} / \mathrm{s}$. Since the interfacial part of the top slab is sitting in an energy well at zero sliding distance (which precludes lateral motion), and the upper part of the top slab moves with $V_{\text {ex }}$ (applied to its topmost layer), a forward (or positive) shearing of the top slab results: this is represented by the regions of $f_{x}>0$ in Fig. 4 and $\Delta X>0$ in Fig. 5(a), and schematically illustrated in Fig. 5(b). Similarly, the top layer (i.e., the interface layer) of the bottom slab tends to move forward with the upper slab, but the bottom layer of the bottom slab is fixed: this causes the bottom slab to also shear forward during the stick regime. Once the top slab reaches 


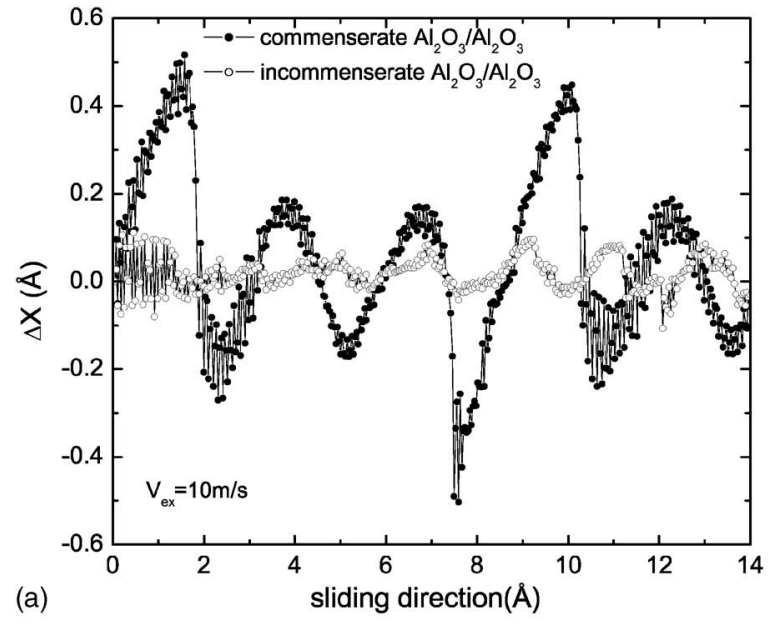

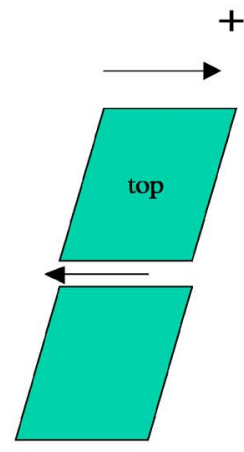

(b) stick

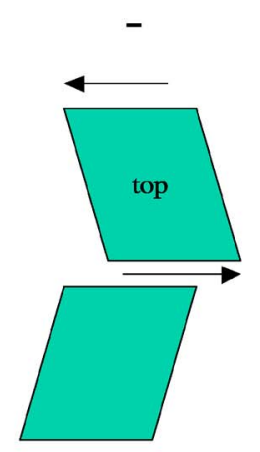

slip

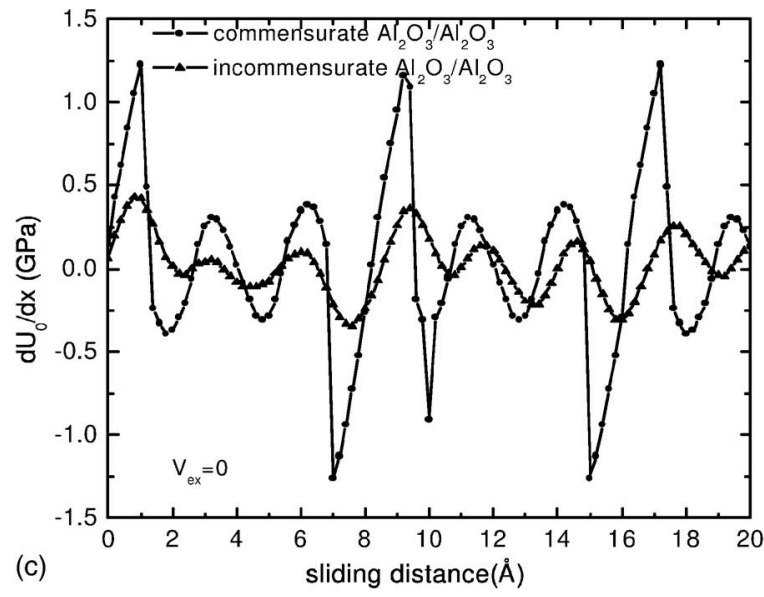

FIG. 5. (Color online) (a) Shearing distance $\Delta X=\left(X_{t}-X_{i}\right)$ (the lateral distance between the outmost layers and that of the interfacial layers) vs sliding distance for commensurate and incommensurate $\alpha-\mathrm{Al}_{2} \mathrm{O}_{3}(0001) / \alpha-\mathrm{Al}_{2} \mathrm{O}_{3}(0001)$ during sliding at $V_{\mathrm{ex}}=10 \mathrm{~m} / \mathrm{s}$. (b) Schematic illustration of the shearing deformation of the two slabs. (c) Numerical derivative of $U_{0}(x)$ with respect to sliding distance on commensurate and incommensurate $\alpha-\mathrm{Al}_{2} \mathrm{O}_{3}(0001) / \alpha-\mathrm{Al}_{2} \mathrm{O}_{3}(0001)$.

the potential peak, it starts to move towards the potential well: the interfacial portion of the top slab "slips" at a velocity that momentarily exceeds $V_{\text {ex }}$, and the system is sheared in a reverse sense (i.e., negative shear). The bottom layers of the top slab tend to move ahead of its top layers, which leads to the negative shear associated with slip [illustrated in Fig. 5(b)]. The bottom slab will relax back to its undeformed shape as slip occurs. Figure 5(a) shows that the actual slip distance (i.e., the sliding distance from maximum $\Delta X$ to minimum $\Delta X)$ is much smaller than the distance through which $\Delta X$ increases during the stick phase. Since the slab is constrained to move at $V_{\mathrm{ex}}$, a negative force is needed to slow the top slab and restore its velocity to $V_{\text {ex }}$. After the slab passes over the transition point [i.e., $d^{2} U(x) / d x^{2}=0$ ], the lateral force again increases from a minimum to a maximum value and a new stick regime begins. This stick-slip motion consists of forward and backward elastic shearing of the layers of both slabs, with the top slab experiencing the greatest shear. The extent of shearing is greatly diminished during incommensurate sliding, as noted in the curve with open circles in Fig. 5(a). Figure 5(c) shows the corresponding forces due to static potential, $d U_{0}(x) / d x$, which clearly indicates the largest value of $\Delta X$ or that the greatest amount of shearing of the slab occurs at $f_{0}^{\max }$. The shearing of the incommensurate interface is lower than that of the commensurate interface since the corresponding maximum lateral force for the incommensurate interface is less than that of the commensurate interface. Because $d U_{0}(x) / d x$ is smaller for the incommensurate interface, the adhesion at the incommensurate interface is smaller, and consequently, the net shearing of the incommensurate interface is smaller. So the smaller the fluctuations in $d U_{0}(x) / d x$, the smaller $f_{0}^{\max }$, which leads to less shearing of the slab prior to slip. Li et al. also noted that stick-slip is related to the shearing deformation of the moving slab in their MD simulations of $\mathrm{Ni}-\mathrm{Al}$ sliding, ${ }^{27}$ but they did not elaborate on the relationship between shear and interfacial energy.

To determine the velocity of the top slab during movement down $U(x)$ without the constraint from the external velocity, we set $V_{\text {ex }}=0$ at a peak in $U(x)$ and found that the slab slipped at $V_{s}=105 \mathrm{~m} / \mathrm{s}$, where $V_{s}$ is defined as the slip velocity. Note that this is an order-of-magnitude greater than $V_{\mathrm{ex}}=10 \mathrm{~m} / \mathrm{s}$ considered in Fig. 5(a).

Since $f_{0}^{\max }$ is smaller for incommensurate $\alpha-\mathrm{Al}_{2} \mathrm{O}_{3}(0001) / \alpha-\mathrm{Al}_{2} \mathrm{O}_{3}(0001)$, we expect kinetic friction during incommensurate sliding to be lower than that at commensurate $\alpha-\mathrm{Al}_{2} \mathrm{O}_{3}(0001) / \alpha-\mathrm{Al}_{2} \mathrm{O}_{3}(0001)$. To demonstrate this, we obtained a relationship between kinetic friction and sliding velocity by first computing the converged time average of the instantaneous frictional force intensity, $\left\langle f_{x}\right\rangle$, through long sliding distances. We then defined the kinetic frictional force intensity (at each $V_{\mathrm{ex}}$ ), $F_{k}$, as

$$
F_{k}=\left\langle f_{x}\right\rangle
$$

and plotted this against $V_{\mathrm{ex}}$. Figure 6 summarizes our computed relationship between $F_{k}$ and $V_{\text {ex }}$, for commensurate and incommensurate $\alpha-\mathrm{Al}_{2} \mathrm{O}_{3}(0001) / \alpha-\mathrm{Al}_{2} \mathrm{O}_{3}(0001)$. As anticipated, $F_{k}$ due to sliding along the commensurate interface is higher than that of the incommensurate interface over the velocity range shown in Fig. 6. However, the behavior of our computed $F_{k}$ for both interface commensurations differs over two $V_{\text {ex }}$ ranges. In $10 \mathrm{~m} / \mathrm{s}<V_{\text {ex }}<200 \mathrm{~m} / \mathrm{s}$ (which we define as the low sliding velocity range), the computed $F_{k}$ are very close (i.e., $0.075-0.1 \mathrm{GPa}$ for the commensurate interface, 


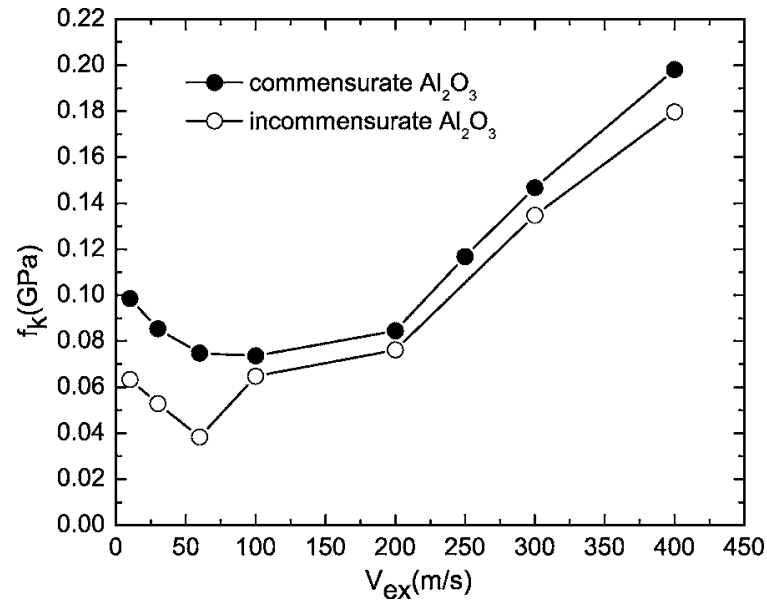

FIG. 6. Kinetic friction force intensity, $F_{k}$, in GPa, as a function of sliding velocity, $V_{\text {ex }}$, in $\mathrm{m} / \mathrm{s}$, for commensurate (closed circle) and incommensurate (open circle) $\alpha-\mathrm{Al}_{2} \mathrm{O}_{3}(0001) / \alpha-\mathrm{Al}_{2} \mathrm{O}_{3}(0001)$.

and $0.04-0.07 \mathrm{GPa}$ for the incommensurate interface), with $F_{k}$ first decreasing and then increasing with $V_{\mathrm{ex}}$. For $V_{\mathrm{ex}}>200 \mathrm{~m} / \mathrm{s}$ (which we define as the high sliding velocity range), $F_{k}$ increases linearly with $V_{\mathrm{ex}}$. Considering the weak dependence of $F_{k}$ on $V_{\text {ex }}$ for $10 \mathrm{~m} / \mathrm{s}<V_{\text {ex }}<200 \mathrm{~m} / \mathrm{s}$, it can be concluded that $F_{k}$ only deviates minimally from Coulombic friction in this range of $V_{\mathrm{ex}}$. For $V_{\mathrm{ex}}>200 \mathrm{~m} / \mathrm{s}, F_{k}$ increases linearly with $V_{\mathrm{ex}}$ in qualitative accord with Stokes' viscous friction law.

The variation of $F_{k}$ on $V_{\text {ex }}$ can be attributed to changes in the shape of $U(x)$ with $V_{\mathrm{ex}}$. If $U(x)$ were symmetric (e.g., a pure cosine), then the sticking and slipping forces would be equal and opposite leading to $F_{k}=0$. For commensurate $\alpha-\mathrm{Al}_{2} \mathrm{O}_{3}(0001) / \alpha-\mathrm{Al}_{2} \mathrm{O}_{3}(0001), U_{0}(x)$ has a nearly symmetrical shape, and the resulting average value of the force due to static potential energy, $\left\langle d U_{0}(x) / d x\right\rangle$, was computed to be $0.007 \mathrm{GPa}$; this is much less than any $F_{k}$ value reported in Fig. 6. So why is $F_{k}$ not close to zero during commensurate sliding? The reason is that the potential energy that the sliding samples experienced with nonzero $V_{\mathrm{ex}}$ is asymmetric around the energy well, i.e., the uphill curve is steeper than the downhill curve. The asymmetry of the potential energy causes the sliding force to change and is especially obvious in the potential curves at lower velocities.

Although the periodicity of $U(x)$ and the absolute values of its hills and valleys are controlled by commensuration, interfacial bonding, and the prevalence of thermal phonons, the shape changes in $U(x)$ are directly related to shearing of the moving upper slab (the bottom slab shears as well, but we focus here on the top slab since we calculated the forces only for the top slab). The extent to which the material shears is contingent on $V_{\mathrm{ex}}$ and $d U_{0}(x) / d x$ (collectively referred to as the system constraints), and the material shear modulus, $G$. The constraints on the top and interface layers of the top slab cause it to change shape (shearing forward and backward during sliding). Irrespective of the shear being forward or backward [following the schematic in Fig. 5(b)], it always adds elastic strain energy to the system. However, during sticking, the shear of the top slab is positive, since $\Delta X>0$, and the accumulation of shearing energy causes the uphill portion of the $U(x)$ energy curve to be steeper compared to $U_{0}(x)$, which is associated with an increase in the sticking force. During the downhill excursions in $U(x)$, or slip regions, where shearing has to change sign from positive to negative, the stored strain energy is suddenly released and then accumulated starting with backward shearing. This release and accumulation of energy results in the softening (i.e., a decrease in the slope of $U(x)$ with sliding distance) of the downhill part of $U(x)$, which leads to a decrease in the sliding force. The softening of $U(x)$ is detailed in the inset figure of Fig. 3(a). As shown in the inset of Fig. 4(a), the maximum $f_{x}$ in Fig. 4(a) at $V_{\mathrm{ex}}=10 \mathrm{~m} / \mathrm{s}$ is $1.32 \mathrm{GPa}$, which exceeds the maximum value of $d U_{0}(x) / d x=1.22 \mathrm{GPa}$. However, the minimum $f_{x}$ is $-1.18 \mathrm{GPa}$, which is less negative than the minimum value of $d U_{0}(x) / d x=-1.25 \mathrm{GPa}$. The asymmetric potential results in the force required to pull the top slab up the barrier (i.e., the sticking force) and to ultimately exceed the force required to restrain the constant velocity movement of the top slap as it moves down the potential barrier (the slipping force). Therefore the accumulation and release of strain energy in the slabs during a stick-slip cycle is largely responsible for the asymmetric shape of $U(x)$.

The $F_{k}$ vs $V_{\text {ex }}$ variations in Fig. 6, i.e., an initial decrease in $10 \mathrm{~m} / \mathrm{s}<V_{\mathrm{ex}}<105 \mathrm{~m} / \mathrm{s}$, followed by an increase over $105 \mathrm{~m} / \mathrm{s}<V_{\mathrm{ex}}<200 \mathrm{~m} / \mathrm{s}$, and then a faster rate of increase for $V_{\mathrm{ex}}>200 \mathrm{~m} / \mathrm{s}$, require a closer look at the terms that affect $U(x)$ over the entire range of $V_{\mathrm{ex}}$ considered. For this purpose, we write $U(x)$ as

$$
U(x)=U_{0}(x)+U_{e}\left(x ; V_{\mathrm{ex}}\right)+U_{p}\left(x ; V_{\mathrm{ex}}\right),
$$

where $U_{e}\left(x ; V_{\mathrm{ex}}\right)$ is the elastic strain energy and $U_{p}\left(x ; V_{\mathrm{ex}}\right)$ is due to thermal phonons. For $10 \mathrm{~m} / \mathrm{s}<V_{\text {ex }}<105 \mathrm{~m} / \mathrm{s}, F_{k}$ is largely determined by $U_{0}(x)$ and the corresponding stored strain energy, $U_{e}\left(x ; V_{\mathrm{ex}}\right)$, since $U_{p}\left(x ; V_{\mathrm{ex}}\right)$ is negligible for small $V_{\text {ex }}$. The accumulation and release of shear strain is responsible for the asymmetric shape of $U(x)$, which leads to larger $F_{k}$ [as noted in Fig. 3(a), $U(x)$ at small $V_{\text {ex }}$ is still very close to $U_{0}(x)$ ]. However, the extent of shear and resulting quantity of stored strain energy are also related to the velocity difference $\Delta V$ where

$$
\Delta V=V_{\text {slip }}-V_{\text {ex }} \text {. }
$$

As $V_{\mathrm{ex}}$ increases, the amount of strain energy released, $U_{e}\left(x ; V_{\mathrm{ex}}\right)$, decreases, thereby decreasing $F_{k}$. As shown in Fig. 3(a), the potential wells become more symmetric at $V_{\text {ex }}=30 \mathrm{~m} / \mathrm{s}$ than at $V_{\text {ex }}=10 \mathrm{~m} / \mathrm{s}$, and in Fig. 4(a), the slip force decreases with increasing $V_{\mathrm{ex}}$, which leads to lower $F_{k}$ with increasing $V_{\text {ex }}$. Once $V_{\text {ex }}$ reaches $V_{s}=105 \mathrm{~m} / \mathrm{s}$, the slab ceases to shear and starts to slide as a rigid body [i.e., $U_{e}\left(x ; V_{\mathrm{ex}}\right)$ drops to zero], but continues to exhibit stick-slip motion in the $105 \mathrm{~m} / \mathrm{s}<V_{\mathrm{ex}}<200 \mathrm{~m} / \mathrm{s}$ range. In this intermediate sliding velocity range, damping from thermal phonons begins to appear since $U_{p}\left(x ; V_{\mathrm{ex}}\right)$ increases. For $V_{\mathrm{ex}}>200 \mathrm{~m} / \mathrm{s}$, stick-slip motion ceases, $F_{k}$ increases due to increasing $U_{p}\left(x ; V_{\mathrm{ex}}\right)$ with a concomitant increase in the "noisiness" of $U(x)$. Hence thermal phonons are largely re- 
sponsible for the damping of the slab motion at high sliding speeds since they wash out any contributions from $U_{0}(x)$.

Some comments regarding friction mechanisms proposed in other modeling efforts are warranted at this point. In our sliding simulations, the entire top slab moved at $V_{\text {ex }}$ and no sudden atom "pops" due to instabilities were observed, which is the friction mechanism suggested in Refs. 25 and 26. For both commensurate and incommensurate $\alpha-\mathrm{Al}_{2} \mathrm{O}_{3}(0001) / \alpha-\mathrm{Al}_{2} \mathrm{O}_{3}(0001)$ interfaces, the decrease in $F_{k}$ at low velocity range, followed by the increase in $F_{k}$ at high velocity range, is markedly different than the dramatic decrease in $F_{k}$ suggested by the MD simulations on hydroxylated $\alpha-\mathrm{Al}_{2} \mathrm{O}_{3}$ slabs in Refs. 49 and 50 (i.e., the kinetic friction force dropped from 17190,1640 , to $65 \mathrm{nN}$ as the velocity increased from $0.5,5$ to $50 \mathrm{~m} / \mathrm{s}$ ).

\section{B. Kinetic friction at incommensurate $\mathrm{Al}(001) / \mathrm{Al}(001)$}

Figure 7 shows $f_{x}$ as a function of sliding distance due to sliding at atomically smooth and atomically rough $\mathrm{Al}(001) / \mathrm{Al}(001)$. Again, the perfect vertical alignment of the centers-of-mass of the top and bottom slabs serves to define the sliding reference. Figure 7 (a) shows that for atomically smooth $\mathrm{Al}(001) / \mathrm{Al}(001)$, there is no stick-slip behavior or periodicity with sliding distance. Rather, noise from lattice phonon vibrations dominates the behavior of $f_{x}$. The maximum lateral force of $0.002 \mathrm{GPa}$ in Table I indicates that there is no energy barrier from the structural configuration for atomically smooth $\mathrm{Al}(001) / \mathrm{Al}(001)$. Therefore thermal vibrations easily wash out the vanishing energy barriers. On the other hand, no shearing occurs since the slip velocity is nearly zero due to the vanishing energy barrier. Therefore, when compared with the $V_{\mathrm{ex}}=30 \mathrm{~m} / \mathrm{s}$ in Fig. 4 for commensurate $\alpha-\mathrm{Al}_{2} \mathrm{O}_{3}(0001) / \alpha-\mathrm{Al}_{2} \mathrm{O}_{3}(0001)$, we find that $f_{x}$ is very small for smooth $\mathrm{Al}(001) / \mathrm{Al}(001)$.

For rough $\mathrm{Al}(001) / \mathrm{Al}(001)$, Figs. $7(\mathrm{~b})$ and $7(\mathrm{c})$ denote fluctuations on top of $f_{x}$ that are superimposed onto $d U_{0}(x) / d x$ (open circles) along the sliding direction. At $V_{\mathrm{ex}}=30 \mathrm{~m} / \mathrm{s}$ [Fig. 7(b)], the periodicity of the static and dynamic cases are nearly identical and stick-slip behavior occurs, despite the large fluctuations in $f_{x}$. However, for $V_{\mathrm{ex}}$ $=60 \mathrm{~m} / \mathrm{s}$ [Fig. 7(c)], the fluctuations due to sliding follow the periodicity of $d U_{0}(x) / d x$ during the early stages of sliding, but the relative difference in spatial periodicities changes around $8 \AA$. This change suggests that stick-slip behavior tends to disappear (at sufficiently large sliding distances) along rough $\mathrm{Al}(001) / \mathrm{Al}(001)$ for sliding velocities in excess of $60 \mathrm{~m} / \mathrm{s}$.

The computed $F_{k}$ for the smooth and rough $\mathrm{Al}(001) / \mathrm{Al}(001)$ sliding samples is shown as a function of sliding velocity in Fig. 8. There is essentially no hint of Coulomb friction behavior at low velocities for either interface. Kinetic friction generally increases linearly with sliding speed which suggests viscous behavior [especially for smooth $\mathrm{Al}(001) / \mathrm{Al}(001)]$. During viscous sliding no shearing of the slabs occurs and frictional damping is due to thermal phonons. Because there is no energy barrier from the structural configuration for smooth $\mathrm{Al}(001) / \mathrm{Al}(001), F_{k}$ is very low at lower sliding velocities. This indicates that $U_{p}(x)$ predominates at a lower $V_{\text {ex }}$ for $\mathrm{Al}(001) / \mathrm{Al}(001)$ more than it does for $\alpha-\mathrm{Al}_{2} \mathrm{O}_{3}(0001) / \alpha-\mathrm{Al}_{2} \mathrm{O}_{3}(0001)$ since the former is much softer than the latter. This result is in qualitative accord with recent experiments of superlubricity, in which very low friction was observed for incommensurate smooth contacts. ${ }^{23-25}$ On the other hand, $F_{k}$ is much higher for rough $\mathrm{Al}(001) / \mathrm{Al}(001)$. At $V_{\mathrm{ex}}=100 \mathrm{~m} / \mathrm{s}$, adhesive wear was noted as some of the top slab atoms transferred to the lower slab. This caused the attendant increase in the slope of the $F_{k}$ vs $V_{\text {ex }}$ curve in Fig. 8 beginning at $V_{\text {ex }}=100 \mathrm{~m} / \mathrm{s}$.

Figure 9 investigates the extent of shear in rough $\mathrm{Al}(001) / \mathrm{Al}(001)$ sliding at $V_{\mathrm{ex}}=60 \mathrm{~m} / \mathrm{s}$. We label the atomic planes in the top slab with numbers 1-8 where the outmost layer is 1 and the interface layer is 8 . Since layer 2 is the first layer without the applied external velocity, $V_{\mathrm{ex}}$, we show the variations of both $\Delta X=\left(X_{8}-X_{2}\right)$ (closed circles) and $\Delta X=\left(X_{6}-X_{2}\right)$ (open circles) with sliding distance. During sliding, there are some fluctuations in $\Delta X$ around zero, which can be attributed to negligible shearing under thermal fluctuation of the material. Although the atoms in the sixth atomic plane move with the top slab, some atoms in the eighth atomic plane or interface layer remain on the surface of the bottom slab and this leads to the downward trend of the solid curve in Fig. 9. Therefore, for rough $\mathrm{Al}(001) / \mathrm{Al}(001)$, the friction forces are required not only to overcome the interfacial potential barrier, but also break bonds between surface atoms and bulk atoms in the top slab. This is an adhesive wear process, which leads to the high values of $F_{k}$ for $V_{\text {ex }} \geqslant 100 \mathrm{~m} / \mathrm{s}$ for rough $\mathrm{Al}(001) / \mathrm{Al}(001)$.

\section{Discussion of normal force, model size, and structual deformation}

It is of interest to briefly consider the relation between normal force and frictional force. It has been pointed out that the origin of Amontons' law, $F=\mu N$, is that an increase in normal force, $F$, results in a proportional increase in the real contact area. Whereas for single asperity contact at the microscopic level, the contact area will not change with normal force, and experiments show that the Amontons' law is not satisfied. ${ }^{15,34,45}$ In this study, the $z$ distance between the top layer of the upper slab and the bottom layer of the lower slab is held constant and is obtained under equilibrium conditions. By varying the $z$ distance around the equilibrium state within a range of $\pm 0.2 \AA$, the normal force will change (i.e., a decrease in the $z$ distance causes $N$ to be more repulsive). However, no corresponding change in $F_{k}$ was observed. This is related to the fact that within this range, there is not much difference in the static interfacial potential $U_{0}(x)$ due to changes in the $z$ distance, and hence $F_{k}$ remains unchanged. This observation is in agreement with experimental results. ${ }^{34,45}$

In the simulations, the shearing of the $\mathrm{Al}_{2} \mathrm{O}_{3}$ slab is very small which can be seen in Fig. 5(a). This suggests that the deformation of the slab is elastic. No plastic deformation was observed for $\alpha-\mathrm{Al}_{2} \mathrm{O}_{3}(0001) / \alpha-\mathrm{Al}_{2} \mathrm{O}_{3}(0001)$ and flat $\mathrm{Al}(001) / \mathrm{Al}(001)$. For the rough $\mathrm{Al}(001) / \mathrm{Al}(001)$ the combined effects of adhesive wear and very minimal plastic deformation lead to a complex velocity dependence behavior 

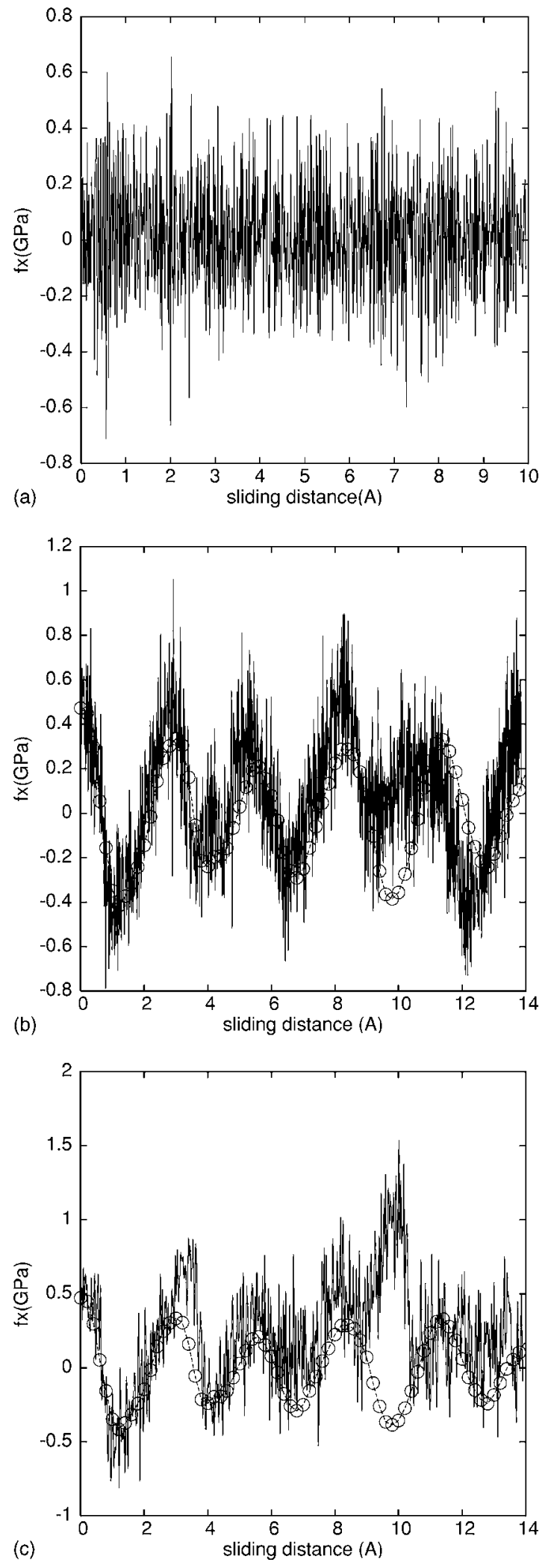

FIG. 7. The instantaneous friction force intensity, $f_{x}$, as a function of sliding distance for (a) smooth $\mathrm{Al}(001) / \mathrm{Al}(001)$ at $V_{\mathrm{ex}}=30 \mathrm{~m} / \mathrm{s}$. (b) Rough $\mathrm{Al}(001) / \mathrm{Al}(001)$ at $V_{\mathrm{ex}}=30 \mathrm{~m} / \mathrm{s}$. (c) Rough $\mathrm{Al}(001) / \mathrm{Al}(001)$ at $V_{\mathrm{ex}}=60 \mathrm{~m} / \mathrm{s}$. In (b) and (c), $d U_{0}(x) / d x$ is also shown (open circles).

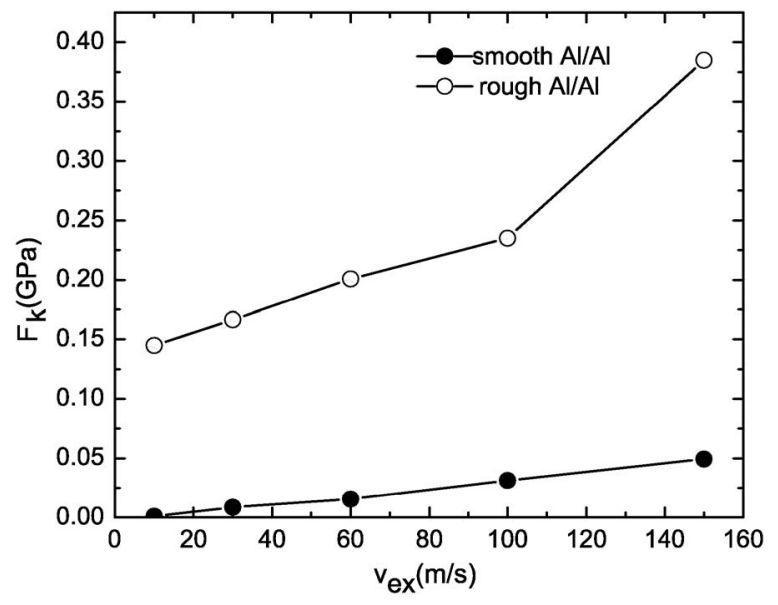

FIG. 8. Kinetic friction force intensity, $F_{k}$, in GPa, as a function of sliding velocity, $V_{\text {ex }}$, in $\mathrm{m} / \mathrm{s}$ for smooth (closed circle) and rough (open circle) $\mathrm{Al}(001) / \mathrm{Al}(001)$.

(with our small model sizes, we could not observe defects such as dislocations, as was the case in Ref. 39). Although our simulations were carried out with a relatively small model (around 1000 atoms), it is highly unlikely that an increase of the model size will change our major results. An interesting aspect to explore for larger model sizes would be the investigation of changes in the potential energy for incommensurate or rough interfaces, due to a possibly shallower total interfacial potential barrier. This would only change the value of frictional force, but not the analysis and conclusions in the present work.

\section{SUMMARY}

Molecular dynamics simulations with the reactive force field have been used to explore sliding friction at atomisticscale $\alpha-\mathrm{Al}_{2} \mathrm{O}_{3}(0001) / \alpha-\mathrm{Al}_{2} \mathrm{O}_{3}(0001)$ and $\mathrm{Al}(001) / \mathrm{Al}(001)$ interfaces. Kinetic friction, which was computed by averag-

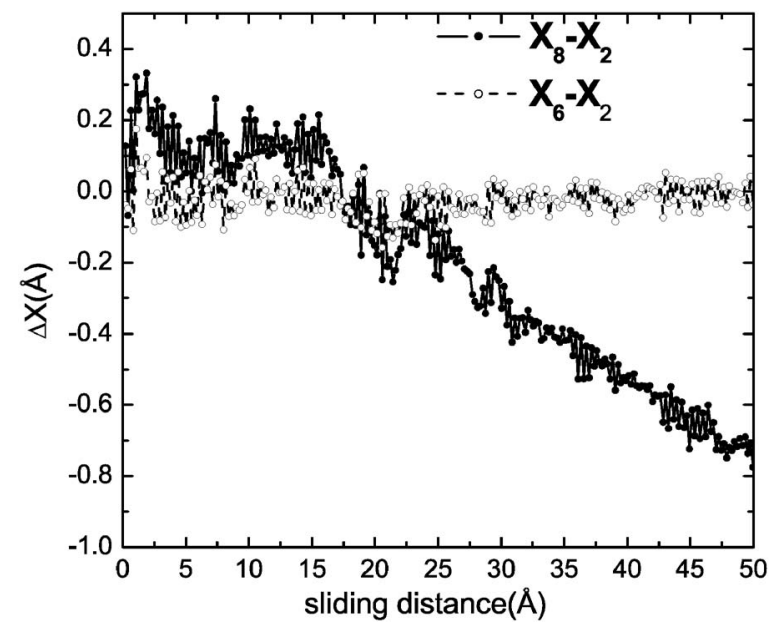

FIG. 9. Shearing distance $\Delta X$ vs sliding distance for rough $\mathrm{Al}(001) / \mathrm{Al}(001)$ sliding at $V_{\mathrm{ex}}=60 \mathrm{~m} / \mathrm{s}$. The open circles correspond to $\Delta X=\left(X_{6}-X_{2}\right)$, and the closed circles correspond to $\Delta X=\left(X_{8}-X_{2}\right)$. 
ing the instantaneous kinetic friction force over sufficiently long sliding distances, minimally deviates from Coulombic behavior during sliding along commensurate $\alpha-\mathrm{Al}_{2} \mathrm{O}_{3}(0001) / \alpha-\mathrm{Al}_{2} \mathrm{O}_{3}(0001)$ up to a sliding velocity of $200 \mathrm{~m} / \mathrm{s}$. As sliding velocity increases from $10 \mathrm{~m} / \mathrm{s}$, kinetic friction decreases up to the slip velocity of $105 \mathrm{~m} / \mathrm{s}$ since progressively smaller quantities of strain energy are released. Between sliding velocities of 105 and $200 \mathrm{~m} / \mathrm{s}$, kinetic friction increases with sliding velocity since viscous damping due to thermal phonons begins to wash out contributions from released strain energy and interfacial adhesion. Beyond $200 \mathrm{~m} / \mathrm{s}$, kinetic friction increases with sliding velocity at a greater rate and is predominantly viscous since damping due to thermal phonons washes out interfacial bonding and the slabs slide as rigid bodies. Similar observations apply for incommensurate $\alpha-\mathrm{Al}_{2} \mathrm{O}_{3}(0001) / \alpha-\mathrm{Al}_{2} \mathrm{O}_{3}(0001)$ although this interface exhibits lower overall kinetic friction. Commensurate $\alpha-\mathrm{Al}_{2} \mathrm{O}_{3}(0001) / \alpha-\mathrm{Al}_{2} \mathrm{O}_{3}(0001)$ shows stick-slip behavior during sliding, whereas stick-slip behavior is less prevalent for incommensurate $\alpha-\mathrm{Al}_{2} \mathrm{O}_{3}(0001) / \alpha-\mathrm{Al}_{2} \mathrm{O}_{3}(0001)$. This behavior is related to the extent to which the interfaces store elastic strain energy in shear (i.e., an incommensurate interface stores less strain energy than a commensurate interface).

Kinetic friction for smooth $\mathrm{Al}(001) / \mathrm{Al}(001)$ tends to follow a Stokes' law since it is proportional to sliding velocity, and shows no hint of Coulombic behavior. No stick-slip behavior is observed for smooth $\mathrm{Al}(001) / \mathrm{Al}(001)$. Kinetic friction for rough $\mathrm{Al}(001) / \mathrm{Al}(001)$ increases with sliding velocity and exceeds that computed for smooth $\mathrm{Al}(001) / \mathrm{Al}(001)$. Stick-slip behavior is observed due to the stronger bonds resulting from missing interfacial atoms due to adhesive transfer. As is the case with thermal phonons, adhesive transfer damps kinetic friction and changes the rate at which kinetic friction increases with sliding velocity.

\section{ACKNOWLEDGMENTS}

The authors wish to acknowledge Dr. Y.T. Cheng for several stimulating discussions on aluminum engine friction and for his careful review of earlier versions of the manuscript, and Dr. M. H. Müser for useful discussions on the results. Support of the Caltech research was provided through a grant form General Motors. The facilities of MSC are supported by funding from ONR-DURIP, ARO-DURIP, and Beckman Institute with additional funding from NSF, NIH, DoE, ONR, DARPA, ChevronTexaco, Seiko-Epson, Aventis Pharma, and Berlex Biopharma. W.A.G. and T.C. wish to thank their friend and colleague the late Dr. Mike Gardos (Hughes Aircraft Co and Raytheon) whose aggressive pursuit of the fundamentals in tribology has stimulated us and many others to help transform tribology into a science.
${ }^{1}$ Principles of Tribology, edited by J. Halling (MacMillan Press, London, 1978).

${ }^{2}$ F. P. Bowden and D. Tabor, The Friction and Lubrication of Solids, Reprint ed. (Oxford University Press, London, 2001).

${ }^{3}$ D. Dowson, History of Tribology, 2nd ed. (American Society of Mechanical Engineers, New York, 1999).

${ }^{4}$ E. D. Smith, M. O. Robbins, and M. Cieplak, Phys. Rev. B 54, 8252 (1996).

${ }^{5}$ G. G. Adams, J. Appl. Mech. 65, 470 (1998).

${ }^{6}$ A. D. Berman, W. A. Ducker, and J. N. Israelachvili, in Physics of Sliding Friction, NATO Advanced Science Institute Series, edited by B. Persson and E. Tosati (Kluwer Academic Publishers, Dordrecht, 1996), Chap. 3, pp. 51-67.

${ }^{7}$ U. Bockelmann, B. Essevaz-Roulet, and F. Heslot, Phys. Rev. Lett. 79, 4489 (1997).

${ }^{8}$ S. D. Mesarovic, J. Mech. Phys. Solids 43, 671 (1995).

${ }^{9}$ F.-J. Elmer, J. Phys. A 30, 6057 (1997).

${ }^{10}$ M. A. Heckel and I. D. Abrahams, J. Sound Vib. 229, 669 (2000).

${ }^{11}$ F. Heslot, T. Baumberger, B. Perrin, B. Caroli, and C. Caroli, Phys. Rev. B 49, 4973 (1994).

${ }^{12}$ M. Enachescu, R. W. Carpick, D. F. Ogletree, and M. Salmeron, J. Appl. Phys. 95, 7694 (2004).

${ }^{13}$ R. Wiesendanger, Scanning Probe Microscopy and Spectroscopy: Methods and Applications (Cambridge University Press, London, 1994).

${ }^{14}$ J. Israelachvili, Intermolecular and Surface Forces With Applications to Colloidal and Biological Systems, 2nd ed. (Academic Press, New York, 1992).
${ }^{15}$ J. Krim, Am. J. Phys. 79, 890 (2002)

${ }^{16}$ J. Krim, D. H. Solina, and R. Chiarello, Phys. Rev. Lett. 66, 181 (1991).

${ }^{17}$ O. Zwörner, H. Hölscher, U. D. Schwarz, and R. Wiesendanger, Appl. Phys. A: Mater. Sci. Process. 66, S263 (1998).

${ }^{18}$ E. Gnecco, R. Bennewitz, T. Gyalog, Ch. Loppacher, M. Bammerlin, E. Meyer and H.-J. Güntherodt, Phys. Rev. Lett. 84, 1172 (2000).

${ }^{19}$ S. Schmid and L. G. Hector, Jr., Wear 215, 257 (1998).

${ }^{20}$ J. A. Harrision, S. J. Stuart, and D. W. Brenner, in Handook of Micro/NanoTribology (CRC Press, Boca Raton, 1999), pp. 525594.

${ }^{21}$ M. O. Robbins and M. H. Müser, in Modern Tribology Handbook, edited by B. Bhushan (CRC Press, Boca Raton, 2001), pp. 717-765.

${ }^{22}$ J. Shimizu, H. Eda, M. Toritsune, and E. Ohumura, Nanotechnology 9, 118 (1998).

${ }^{23}$ G. A. Tomlinson, Philos. Mag. 7, 905 (1929).

${ }^{24}$ E. Gnecco, R. Bennewitz, T. Gyalog, and E. Meyer, J. Phys.: Condens. Matter 13, R619 (2001).

${ }^{25}$ G. He, M. H. Muser, and M. O. Robbins, Science 284, 1650 (1999); M. H. Muser and M. O. Robbins, Phys. Rev. B 61, 2335 (2000).

${ }^{26}$ M. H. Müser, Phys. Rev. Lett. 89, 224301 (2002).

${ }^{27}$ B. Li, P. C. Clapp, J. A. Rifkin, and X. M. Zhang, J. Appl. Phys. 90, 3090 (2001).

${ }^{28}$ J. S. Helman, W. Baltensperger, and J. A. Holyst, Phys. Rev. B 49, 3831 (1994).

${ }^{29}$ J. B. Sokoloff, Phys. Rev. B 65, 115415 (2002). 
${ }^{30}$ M. Hirano and K. Shinjo, Phys. Rev. B 41, 11837 (1990).

${ }^{31}$ M. R. Sørensen, K. W. Jacobsen, and P. Stoltze, Phys. Rev. B 53, 2101 (1996).

${ }^{32}$ M. Hirano, K. Shinjo, R. Kaneko, and Y. Murata, Phys. Rev. Lett. 67, 2642 (1991).

${ }^{33}$ M. Hirano, K. Shinjo, R. Kaneko, and Y. Murata, Phys. Rev. Lett. 78, 1448 (1997).

${ }^{34}$ M. Dienwiebel, G. S. Verhoeven, N. Pradeep, J. W. M. Frenken, J. A. Heimberg, and H. W. Zandergen, Phys. Rev. Lett. 92, 126101 (2004).

${ }^{35}$ Y. Qi, Y. T. Cheng, T. Cagin, and W. A. Goddard, III, Phys. Rev. B 66, 085420 (2002).

${ }^{36}$ D. H. Hwang and K. H. Z. Gahr, Wear 255, 365 (2003).

${ }^{37}$ D. G. Flom and R. Komanduri, Wear 252, 401 (2002).

${ }^{38}$ B. Vick, M. J. Furey, and K. Iskanda, Tribol. Trans. 42, 888 (1999).

${ }^{39}$ E. Hammerberg, B. L. Holian, T. C. Germann, and R. Ravelo, Metall. Mater. Trans. A 35, 2471 (2004).

${ }^{40}$ X. Y. Fu, M. L. Falk, and D. A. Rigney, Wear 250, 420 (2001).

${ }^{41}$ J. Röder, J. E. Hammerberg, B. L. Holian, and A. R. Bishop,
Phys. Rev. B 57, 2759 (1998).

${ }^{42}$ Q. Zhang, T. Cagin, A. C. T. van Duin, W. A. Goddard, III, Y. Qi, and L. Hector, Jr., Phys. Rev. B 69, 045423 (2004).

${ }^{43}$ A. C. T. van Duin, S. Dasgupta, F. Lorant, and W. A. Goddard, III, J. Phys. Chem. A 105, 9396 (2001).

${ }^{44}$ A. C. T. van Duin, A. Strachan, S. Stewman, Q. Zhang, X. Xu, and W. A. Goddard, III, J. Phys. Chem. A 107, 3803 (2003).

${ }^{45} \mathrm{~K}$. Wefers and C. Misra, Oxides and Hydroxides of Aluminum, Alcoa Technical Paper No. 19, Revised, Alcoa Laboratories, Alcoa Center, PA 1987.

${ }^{46}$ D. J. Siegel, L. G. Hector, Jr., and J. B. Adams, Phys. Rev. B 65 , 085415 (2002).

${ }^{47}$ P. Guénard, G. Renaud, A. Barbier, and M. Gautier-Soyer, Surf. Rev. Lett. 5, 321 (1997).

${ }^{48}$ A. Wander, B. Searle, and N. M. Harrison, Surf. Sci. 458, 25 (2000).

${ }^{49}$ D. J. Mann, L. Zhong, and W. L. Hase, J. Phys. Chem. B 105, 12032 (2001).

${ }^{50}$ H. W. Xie, K. Song, D. J. Mann, and W. L. Hase, Phys. Chem. Chem. Phys. 4, 5377 (2002). 